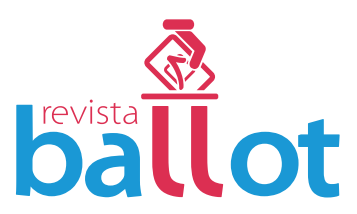

\title{
A tutela inibitória no Direito Eleitoral Brasileiro
}

Paula Saleh (Universidade de Coimbra, Portugal)

psaleh@uol.com.br

Faculdade de Direito - Pátio da Universidade

3004-545 Coimbra 


\begin{abstract}
We have demonstrated throughout this paper the importance of the use of preventive protection, in particular the Injunction and their importance to the Electoral Law. The inhibitory guardianship aims to prevent illicit, preventing the practice and the continuation or repetition, culminating to introduce itself in that way, as a protection to its previous practice and not as a dedicated ward for the past, as is the case with traditional "tutela ressarcitória". It is therefore a guardianship turned to the future. Finally, we will analyze some judged from Regional Electoral Courts and the Supreme Electoral Tribunal to understand the need of using this type of action.
\end{abstract}

Keywords: civil procedure, preventive control, effective guardianship of rights, inhibitory guardianship, electoral law

\title{
Resumo
}

Demonstramos ao longo deste artigo a importância do uso da tutela preventiva, em especial a Ação Inibitória e sua importância no Direito Eleitoral. A tutela inibitória visa a prevenir o ilícito, impedindo a prática, a continuação ou a sua repetição, culminando por apresentar-se assim, como uma tutela anterior à sua prática, e não como uma tutela voltada para o passado, como a tradicional tutela ressarcitória. É sim uma tutela voltada para o futuro. Por fim, analisaremos alguns julgados dos Tribunais Regionais Eleitorais e do Tribunal Superior Eleitoral para entendermos a necessidade do uso deste tipo de ação.

Palavras-chave: processo civil, tutela preventiva, tutela efetiva dos direitos, ação inibitória, direito eleitoral 


\section{Introdução}

Diante da ocorrência de um ato ilícito que tenha causado prejuízos, não há dúvidas que se possa manejar uma ação para fazer cessar o ato, desfazer o ilícito ou o dano e, ainda, ressarcir os prejuízos dele advindos.

Assim, como dito, diante da concretude de um prejuízo causado por um ato ilícito, o ordenamento jurídico prevê um leque imenso de possibilidades para se fazer voltar à normalidade jurídica, ações ressarcitórias, de obrigação de fazer, de dar, de não fazer, etc.

Entretanto, se estivermos diante de um ato ilícito que ainda não ocorreu, ou seja, que ainda não se iniciou no tempo e, consequentemente, não se concretizou no mundo jurídico, mas que tenha possibilidade real de vir a ser perpetrado, pergunta-se: pode-se reclamar a prestação jurisdicional do Estado a fim de impedir a realização de um ato ilícito futuro?

O ordenamento jurídico brasileiro prevê, na seara cível, três instrumentos aptos a tutelar este direito a não se ver prejudicado futuramente por um ato ilícito: 1) Habeas Corpus Cível Preventivo ${ }^{1}$; 2) Mandado de Segurança Preventivo ${ }^{2}$ e 3 ) Tutela Inibitória.

Nossa análise se dará em torno da tutela inibitória, acerca da qual iremos verificar os pressupostos, legitimidade, causa de pedir e natureza jurídica, bem como sua relação com o direito eleitoral.

Verificaremos que o direito eleitoral é o ramo no qual também se destaca a inibição, analisando assim, algumas decisões dos Tribunais Regionais Eleitorais e do Tribunal Superior Eleitoral, para que possamos ver na prática como estes Tribunais vem tratando desta importantíssima criação doutrinária.

1. Constituição Federal, Artigo $5^{\circ}$ : LXVII - não haverá prisão civil por dívida, salvo a do responsável pelo inadimplemento voluntário e inescusável de obrigação alimentícia e a do depositário infiel; LXVIII - conceder-se-á 'habeas-corpus' sempre que alguém sofrer ou se achar ameaçado de sofrer violência ou coação em sua liberdade de locomoção. Neste sentido: STJ - HC n. 34.014, STJ - Relatora Ministra Maria Isabel Gallotti. Alimentos. Habeas Corpus Preventivo. Cabimento. Recurso Parcialmente provido."(...) Caberá habeas corpus, preventivamente, mesmo não havendo decreto prisional, quando evidenciado o risco de contrição à liberdade do paciente". Precedentes. Recurso parcialmente provido. E, ainda: STJ - HC n. 156.823 - Relator: Ministro Honildo Amaral de Mello Castro. Execução e Revisional de Alimentos. Ameaça de prisão. Decisão que manda pagar a integralidade do débito alimentar revisionado por outro juízo. Concessão de ordem do HC Preventivo.

2. "No contexto de impetração de ordem preventiva de segurança, o objetivo é o de evitar a formação do ato danoso, o que exclui, logicamente, a prova de sua existência, pois o que se pretende é exatamente impedir que tal ato se forme(exista como fenômeno juridicamente relevante)". MAIA, Napoleão Nunes. In Estudos Processuais sobre o Mandado de Segurança. UFC. 2a Edição, 2002. Pag. 176. Neste sentido: STF. Medida Cautelar em Mandado de Segurança 26.900-6 Distrito Federal -Ministro Eros Grau. "Defiro em parte o pedido liminar para que seja garantido aos impetrantes o livre acesso e presença ao Plenário do Senado por ocasião da Sessão Deliberativa Extraordinária destinada à apreciação do Projeto de Resolução 53/2007 (...)" 


\section{O sentido da Tutela Jurisdicional Preventiva}

Ao criar a jurisdição ${ }^{3}$ no quadro de suas instituiçóes, visou o Estado garantir que as normas de direito substancial - contidas no ordenamento jurídico fossem efetivamente conduzidas aos postulados enunciados. Procurou assegurar a obtenção, na experiência concreta, daqueles preciosos resultados práticos que o direito material preconiza ${ }^{4}$. Por meio do exercício da função jurisdicional, o Estado busca fazer com que se atinjam, em cada caso concreto, os objetivos das normas de direito substancial, fazendo-se justiça e alcançando-se a paz social ${ }^{5}$.

E para que o Estado possa exercer fielmente o seu dever de solucionar os conflitos de interesses, impondo o império da Lei, dando proteção aos direitos envolvidos no litígio, necessariamente precisa conceder a todos, indistintamente, o poder de levar as suas pretensões ao órgão jurisdicional. Mesmo as pretensões infundadas, esdrúxulas ou eivadas de má-fé dever ser conhecidas pelo Poder Jurisdicional, pois somente dessa maneira poderá ele constatar a quem a lei concede proteção em um dado conflito de interesses, para que então possa concedê-la ${ }^{6}$.

É garantia constitucional do direito de ação, do direito de acesso à atividade jurisdicional do Estado, que, embora ínsita à própria noção de Estado de Direito ${ }^{7}$, é comum ser expressamente prevista pelos textos constitucionais, como no caso do brasileiro, dispondo, no art. $5^{\circ}$, XXXV, que "a lei não excluirá da apreciação do Poder Judiciário, lesão ou ameaça a direito".

Quando, motivado pelo exercício do direito constitucional de ação, o órgão jurisdicional desenvolve a sua atividade de apreciação da pretensão feita pela parte e constata que o interesse por ela deduzido é juridicamente protegido, que se trata efetivamente de um direito lesado ou ameaçado, deverá então conceder-lhe a tutela jurisdicional, para que seja resguardado contra a lesão ou ameaça sofrida. Deverá fazer com que se dê, na prática, na medida do possível, o exato resultado pretendido pela norma de direito material ${ }^{8}$.

Assim, quando a atividade jurisdicional de depara com a efetiva existência de um direito, de um interesse juridicamente protegido, deve conceder-lhe a tutela que o assegura. Quando

3. Jurisdição é a atividade mediante a qual os juízes estatais examinam as pretensões e resolvem os conflitos. Caracterizando-se como a capacidade, que o Estado tem de decidir imperativamente e impondo decisóes. O que distingue a jurisdição das demais funções do Estado (legislação, administração) é precisamente, em primeiro plano, a finalidade pacificadora com que o Estado a exerce. É para a consecução dos objetivos da jurisdição e particularmente daquele relacionado co a pacificação com justiça, que o Estado institui o sistema processual, ditando normas a respeito (direito processual), criando órgãos jurisdicionais, fazendo despesas com isso e exercendo através deles o seu poder. GRINOVER, Ada Pellegrini; CINTRA, Antônio Carlos de Araújo; e DINAMARCO, Cândido Rangel. Teoria Geral do Processo, Editora Malheiros: São Paulo. 2004. Págs. 23-24.

4. GRINOVER, Ada Pellegrini; CINTRA, Antônio Carlos de Araújo; e DINAMARCO, Cândido Rangel. Teoria Geral do Processo, São Paulo: Malheiros. 2004. Pág. 131.

5. Cândido Rangel Dinamarco bem ressalta que a jurisdição também possui um escopo social, que é a pacificação com justiça. A instrumentalidade do processo, 6 ed., São Paulo: Malheiros. 1998. 160-167.

6. José Roberto dos Santos Bedaque, Tutela Cautelar e tutela antecipada: tutelas sumárias e de urgência (tentativa de sistematização). São Paulo: Malheiros, 1998.,p. 58.

7. GONZÁLES Perez, Jesus, El derecho a la tutela jurisdicional, 2. Ed., Madrid: Civitas, 1989. Pg. 22.

8. SPADONI, Joaquim Felipe. Ação Inibitória. A ação preventiva prevista no art. 461 do CPC, $2^{\circ}$ ed., São Paulo: RT, 2007,pg. 23. 
no desenvolver da atividade se verifica que a apreciação de "afirmativa" de direito é, na realidade, apreciação de direito (porque sua existência foi constatada), deverá conceder-lhe a tutela jurisdicional à qual está obrigado.

Dessa forma, a apreciação de direito existente lesado ou ameaçado implica concessão de tutela jurisdicional ao seu titular. Apreciação de direito passa a significar, portanto, tutela jurisdicional. $\mathrm{O}$ direito constitucional de ação ${ }^{9}$ é visto não apenas como uma garantia de mera possibilidade de acesso aos órgãos jurisdicionais, mas como uma garantia constitucional de acesso a uma atividade jurisdicional adequada e eficaz à tutela do direito que porventura venha a ser constatado ${ }^{10}$.

Para que seja assegurada a adequada tutela jurisdicional de um determinado direito, não é suficiente que seja previamente posto um procedimento qualquer, que lhe assegure uma tutela meramente formal ou abstrata, mas sim um procedimento estruturado de modo a poder the oferecer uma tutela efetiva. Dessa forma, o instrumento por meio do qual se exterioriza deve estar predisposto a permitir a participação das partes nos debates e na produção de provas, concedendo-lhes os instrumentos necessários para a defesa das pretensóes aduzidas em juízo ${ }^{11}$.

A tutela concedida pelo Poder Judiciário deve se aproximar, o máximo possível, daquele resultado que seria obtido pelo respeito espontâneo ao direito. Na lição de Chiovenda,"O processo deve dar, quanto for possivel praticamente, a quem tenha um direito, tudo aquilo e exatamente aquilo que ele tenha direito de conseguir" ${ }^{12}$. Assim, o processo civil ${ }^{13}$ deve estar estruturado de modo a viabilizar a adequada tutela dos direitos ${ }^{14}$.

No Estado Liberal sempre prevaleceu a tendência de se privilegiar os valores da liberdade individual perante os poderes estatais, com base em uma rígida observância do princípio da divisão dos poderes, o que se refletiu na elaboração teórica do conceito de jurisdição.

Estabelecida a premissa de que a relação jurídica entre os cidadãos era de domínio exclusivo dos indivíduos nela envolvidos, a jurisdição foi entendida como uma intervenção autoritária sempre sucessiva à violação da ordem jurídica, tendo por função, mais especificamente, a reintegração do direito subjetivo violado. Por consequência, excluía-se a função preventiva

9. É preciso compreender que o direito de ação não pode mais ser pensado como um simples direito à sentença, mas sim como o direito ao modelo processual capaz de propiciar a tutela do direito afirmado em juízo.

10. Proto Pisani, Lezione di diritto processuale, p. 34-36; Jesús Gonzales Pérez, El derecho a la tutela jurisdicional, p. 21-22; Ada Pellegrini Grinover, As garantias constitucionais do direito de ação, p. 153-157; Luis Guilherme Marinoni, Novas linhas do processo civil, p. 110-115; Carmen Lúcia Antunes Rocha, O direito constitucional à jurisdição, As garantias do cidadão na justiça, p. 34-42.

11. SPADONI, Joaquim Felipe. Op. Cit., pgs. 25-26.

12. Instituições de direito processual civil. Campinas: Bookseller, 1998. Vol. 1, pg. 67.

13. O processo civil funda-se sobre o paradigma de uma jurisdição meramente declarativa, que oculta as especifidades das relações entre direito material e direito processual. Sendo assim, o direito é visto como algo posto, algo pré-dado, absolutamente pressuposto que, em juízo, é meramente declarado, ou, então, como resultado exclusivo de um procedimento, produto da decisão judicial. Assim, é compreensível a dificuldade enfrentada para a construção de "uma tutela processual que tenha natureza puramente preventiva". BAPTISTA DA SILVA, Ovídio Araújo. Racionalismo e tutela preventiva. In Sentença é coisa julgada. $4^{\circ}$ ed. revisada e ampliada. Rio de Janeiro: Forense, 2006. Pg. 265.

14. A função do juiz, nessa concepção, seria apenas revelar o que está posto, o direito já pré-dado ou, de outro lado, o resultado da decisão do juiz é sempre o direito. 
do poder jurisdicional, já que essa função determinaria um ampliamento dos poderes de controle do Estado-juiz e uma limitação da liberdade de autônoma regulamentação das relações jurídicas privadas ${ }^{15}$.

Destarte, diante da mudança do panorama jurídico e político, com o advento do Estado Social e com as previsões de garantias processuais estabelecidas nas Constituições, formas de tutela jurisdicional preventiva começaram a ser pensadas pelos juristas e admitidos pelos mais variados ordenamentos jurídicos, destacando-se, no direito brasileiro, a tutela cautelar, a tutela antecipada e a tutela inibitória ${ }^{16}$.

Ao exercer também uma função preventiva, a jurisdição deixa de ser vista como uma atividade estatal atuada apenas após a ocorrência da violação do direito, com o fim de repor as coisas ao status quo ante, na forma em que foi concebida durante o Estado Liberal, para assumir também o papel de prevenção de atos contrários à ordem jurídica estabelecida, intervindo na relação dos particulares antes mesmo de se caracterizar o ato violador do direito, para que este se realize na exata forma prevista pelo ordenamento jurídico ${ }^{17}$.

\section{Breves considerações sobre a tutela inibitória no Brasil}

A tutela preventiva definitiva só era prevista para casos específicos, mais ligados à tutela de direitos patrimoniais, como no interdito proibitório e nunciação de obra nova.

Entretanto, o panorama jurídico brasileiro começou a se modificar com o advento de leis que buscaram reformar o sistema processual civil, destacando-se a Lei 8.952/1994, que deu a nova redação ao artigo $461{ }^{18}$, do Código de Processo Civil.

Verificou-se, com essa nova previsão legislativa, que a tutela específica das obrigações de conduta, positiva ou omissiva, viabilizando não só uma atuação jurisdicional com fim repressivo, buscando a reintegração na forma específica do direito já violado, mas também uma tutela preventiva e definitiva de um direito ameaçado de violação.

Através disso, instituiu-se, no sistema processual brasileiro, a ação e tutela que tem sido denominada pela doutrina nacional e internacional como "inibitória" ${ }^{19}$, utilizável na proteção preventiva de todo e qualquer direito relacionado a uma obrigação de fazer ou não-fazer.

Segundo Joaquim Felipe Spadoni, jurista brasileiro que se debruça sobre o tema, a tutela inibitória é aquela que tem por objetivo alcançar um provimento judicial apto, que impeça " $a$

15. Cristina Rapisarda, Profille della tutela civile inibitória, Padova: Cedam, 1987. P. 18.

16. SPADONI, Joaquim Felipe, Op. Cit., pg. 28.

17. Gian Antonio Micheli, Derecho procesal civil. La acción preventiva, Buenos Aires: EJEA, 1970, vol. 4, p. 413 .

18. Artigo 461, CPC: Na ação que tenha por objeto o cumprimento de obrigação de fazer ou não fazer, o juiz concederá a tutela específica da obrigação ou, se procedente o pedido, determinará providências que assegurem o resultado prático equivalente ao do adimplemento.

19. O direito italiano mesmo trata como "Tutela Civile Inibitoria"; o Direito Anglo-Americano trata como "Injunction" ou "Injuctive Relief"; e o direito Alemão "Deliktische Unterlassungklage". Ambas com o mesmo significado para Ação Inibitória. 
prática, continuação ou repetição do ato ilícito" ${ }^{20}$. Assim, possibilita que o direito seja usufruído in natura pelo seu titular, tal como permite o ordenamento jurídico.

No mesmo sentido afirma Luis Guilherme Marinoni:

"A tutela inibitória é prestada por meio de ação de conbecimento, e assim não se liga instrumentalmente a nenhuma ação que possa ser dita "principal". Trata-se de "açẫo de conhecimento" de natureza preventiva, destinada a impedir a prática, a repetição ou a continuação do ilícito. ${ }^{21} 22$

A tutela inibitória é uma tutela específica, pois objetiva conservar a integralidade do direito, assumindo importância não apenas porque alguns direitos não podem ser reparados e outros não podem ser adequadamente tutelados através da técnica ressarcitória, mas também porque é melhor prevenir do que ressarcir, o que equivale dizer que, no confronto entre a tutela preventiva e a tutela ressarcitória, deve-se dar preferência à primeira.

A tutela ressarcitória, na maioria das vezes, substitui o direito originário por um direito de crédito equivalente ao valor do dano verificado e, nesse sentido, tem por escopo apenas garantir a integralidade patrimonial dos direitos; já a inibitória, que não tem qualquer caráter sub-rogatório, destina-se a garantir a integralidade do direito $\mathrm{em} \mathrm{s}^{23}$.

Ou seja, enquanto a tutela ressarcitória visa ao retorno da vigência da norma, após a violação, a tutela inibitória pretende que a norma não seja sequer violada, daí a superioridade da técnica da segunda sobre a primeira.

A tutela inibitória é caracterizada por ser voltada para o futuro, independentemente de estar sendo dirigida a impedir a prática, a continuação ou a repetição do ilícito, este tem que ser um ato do porvir. Ressalte-se que a inibitória, ainda que empenhada apenas em fazer cessar o ilícito ou a impedir a sua repetição, não perde a sua natureza preventiva, pois não tem por fim reintegrar ou reparar o direito violado ${ }^{24}$.

20. SPADONI, Joaquim Felipe. Ação inibitória: a ação preventiva prevista no art. 461 do CPC. São Paulo: RT,2002. p.66.

21. MARINONI, Luis Guilherme. Tutela Inibitória e tutela de remoção do ilícito. Artigo publicado no site: http://jus.com,br/artigos/5041/tutela-inibitoria-e-tutela-de-remocao-do-ilicito\#ixzz32AXKJIo8

22. Nesse sentido: A sua proposta revela, assim, a inibição para que o ato não ocorra, não prossiga ou não se repita. (...) A tutela inibitória cumpre, assim, os postulados da efetividade, posto preventiva, e da especificidade, haja vista conferir a utilidade esperada acaso não houvesse a ameaça de violação. Evita o ilícito ao invés de propor-lhe a reparação, garantindo o exercício integral da aspeiração do jurisdicionado, rompendo o dogma de que o ressarcimento é a única forma de tutela contra o ilícito. (Superior Tribunal de Justiça RECURSO ESPECIAL No 1.019.314 - RS (2007/0307980-6) RELATOR : MINISTRO LUIZ FUX) E, ainda: Constitui, pois, forma de proteção específica de direitos, em especial aqueles de caráter extrapatrimonial, cuja violação não é adequadamente reparada pela via indenizatória - diante da impossibilidade de se mensurar economicamente sentimentos e emoções - assumindo propósito meramente consolatório, de compensar a vítima pelo sofrimento suportado.(Superior Tribunal de Justiça RECURSO ESPECIAL No 1.388.994 - SP (2013/0110749-5) RELATORA : MINISTRA NANCY ANDRIGHI.

23. Cristina Rapisarda, Digesto delle discipline privatistiche, vol. 9, p. 476,

24. MARINONI, Luis Guilherme. Tutela Inibitória Individual e Coletiva. $5^{\circ}$ ed., São Paulo: Editora Revista dos Tribunais, 2012, pg. 34. 


\section{Da fundamentação jurídica}

O maior fundamento da ação inibitória encontra-se na própria Constituição Federal, precisamente no artigo $5^{\circ}, \mathrm{XXXV}$, que estabelece que "a lei não excluirá da apreciação do Poder Judiciário, lesão ou ameaça a direito", e exatamente por isso, não há como pensar que a inibitória somente pode servir a certos direitos, pois este dispositivo garante o direito à adequada tutela jurisdicional e, assim, o direito à técnica processual capaz de viabilizar o exercício do direito à tutela inibitória ${ }^{25}$.

O direito de acesso à justiça garante a técnica processual capaz de prestar a efetiva tutela dos direitos, e não propriamente a tutela do direito. A tutela é decorrência da existência do próprio direito. Assim, a tutela inibitória existe pelo fato de ser inerente à existência do direito; todo titular do direito tem o direito de impedir a sua violação.

Nesse contexto, Marinoni afirma que há direito fundamental à efetividade da tutela jurisdicional e, assim, direito fundamental à tutela preventiva, o qual incide sobre o legislador - obrigando-o a instituir as técnicas processuais capazes de permitir a tutela preventiva - e sobre o juiz - obrigando-o a interpretar as normas processuais de modo a delas retirar instrumentos processuais que realmente viabilizem a concessão de tutela de prevenção ${ }^{26}$.

Não obstante, pode-se afirmar que a tutela inibitória se funda no próprio direito material. Se várias situações de direito substancial, diante de sua natureza, são absolutamente invioláveis, é evidente a necessidade de se admitir uma ação de conhecimento preventiva. Do contrário, as normas que proclamam direitos, ou objetivam proteger bens fundamentais, não teriam qualquer significação prática, pois poderiam ser violadas a qualquer momento, restando somente o ressarcimento do dano.

Spadoni ${ }^{27}$ dividiu o fundamento da inibitória em substancial e processual. Por fundamento substancial entende-se o direito ao devido cumprimento da obrigação, sendo que o processual encontra viabilidade no artigo 461 e 461-A do Código de Processo Civil.

\footnotetext{
25. Rapisarda e Taruffo afirmam que o artigo 24 da Constituição da República Italiana garante o direito à tutela inibitória: "È precisamente in questo âmbito Che si colloca la fuizione della tutela inibitória, anche al di là dei casi expressamente previsti dalla legge, proprio in quanto essa è diretta a fornire uno strumento di garanzia giurisprudenzionale per quelle situazioni sostanziali che non trovano tutela, o vengono tutelare in modo inadeguato, dagli strumenti restitutori o risarcitori. In sostanza, la concezione meramente risarcitoria della tutela di condana apre dei vuoti di grande rilievo nell'attuazione concreta della garanzia di ciu all'art. 24, I co., Cost.: per contro, l'estensione di tale garanzia alle situazioni sostanziali non tutelabili in via risarcitoria impone di ammettere per esse la tutela inibitória. Essa deve, quindi, essere atípica, próprio per Poter slvolgere la funzione generale di tutela prevista dalla norma constituzionale" (Cristina Rapisarda e Michele Taruffo, Inibitpria, Enciclopedia giuridica Treccani, vol. 17, p. 9).

26. MARINONI, Luis Gulherme. Tutela Inibitória e tutela de remoção do ilícito. Artigo publicado no site: http://jus.com,br/artigos/5041/tutela-inibitoria-e-tutela-de-remocao-do-ilicito\#ixzz32AXKJIo8

27. SPADONI, Joaquim Felipe. Ação inibitória: a ação preventiva prevista no art. 461 do CPC. São Paulo: RT,2002.
} 


\section{Dos pressupostos}

O ajuizamento de uma ação inibitória objetiva evitar a violação de um direito do autor, pela ré, a ser efetivada pelos atos que estejam em desacordo com o existente dever de conduta. Pretende-se ver garantidos a integralidade e o respeito ao direito afirmado, que depende, a princípio, de uma conduta ilícita do devedor, prevista em lei ou em contrato.

O que tem um autor de uma ação inibitória em vista é, assim, impedir que um ato violador do direito seja praticado, ou fazer cessar uma conduta dessa natureza já iniciada, mas que continua ou que pode se repetir.

A ação inibitória se volta contra a possibilidade do ilícito, ainda que se trate de repetição ou continuação. É voltada para o futuro, e não para o passado. De modo que nada tem a ver com o ressarcimento do dano e, por consequência, com os elementos para a imputação ressarcitória - os chamados elementos subjetivos, culpa ou dolo. ${ }^{28}$

Além disso, essa ação não requer nem mesmo a probabilidade do dano, contentando-se com a simples probabilidade de ilícito (ato contrário ao direito). Inclusive esse fundamento foi totalmente adotado pelo Novo Código de Processo Civil, Lei 13.105/2015, na íntegra do parágrafo único do artigo 497: "Para a concessão da tutela específica destinada a inibir a prática, a reiteração ou a continuação de um ilícito, ou a sua remoção, é irrelevante a demonstração da ocorrência de dano ou da existência de dolo ou culpa" 2930.

Imaginar que a ação inibitória se destina a inibir o dano implica na suposição de que nada existe antes dele que possa ser qualificado de ilícito civil. Acontece que o dano é uma consequência eventual do ato contrário ao direito, os quais, assim, podem e devem ser destacados para que os direitos sejam mais adequadamente protegidos ${ }^{31} 32$.

Nesse sentido, ato ilícito vem a ser aquele "contrário ao direito, violador de um dever estabelecido por uma norma jurídica originada em lei ou contrato". Torna-se importante ressaltar que o artigo 186 do Código Civil ${ }^{33}$ não conceitua o que seja ato ilícito, ele apenas prevê a

28. MARINONI, Luis Guilherme. Tutela Inibitória individual e coletiva. $5^{\circ}$ Edição. 2012. Editora Revista dos Tribunais. São Paulo.

29. Conforme o Novo CPC Comentado pelo Professor Cássio Scarpinella Bueno: "O Parágrafo único é novidade na perspectiva textual, espelhando segura e correta orientação doutrinaria ao evidenciar a desnecessidade de ocorrência de dano, culpa ou dolo nos casos em que a tutela específica é dirigida a inibir a prática, reiteração ou a continuação de ilícito". Novo Código de Processo Civil Anotado. São Paulo: Saraiva, 2015.

30. Nesse ponto específico, o Novo CPC adotou integralmente a posição adotada pelo Ilustre Professor Doutor Aldo Frignani, em 1974, sendo o pioneiro ao tratar dessa matéria quando da publicação de sua monumental obra L'injunction nella common law el inibitória nem diritto italiano, Milano: Giufrè, p. 413

31. Nesse sentido:"a probabilidade de que um ato venha a ser praticado contra uma conduta legal sancionada é o bastante para surgir o interesse processual no manejo da tutela de inibição" (Superior Tribunal de Justiça RECURSO ESPECIAL No 1.019.314 - RS (2007/0307980-6) RELATOR : MINISTRO LUIZ FUX

32. Embora quem pratique o ato danoso em estado de necessidade seja obrigado a reparar o dano causado, o mesmo não acontece com aquele que o pratica em legitima defesa, no exercício regular do direito e no estrito cumprimento do dever legal. Para que se configurem as excludentes da Responsabilidade Civil que autorizem o dano e a obediência a certos limites. De sorte que o excesso na legitima defesa já possui caráter antijurídico e, dá azo a reparação.

33. Ver artigo 186, CC/Br: "Aquele que, por ação ou omissão voluntária, negligência ou imprudência, violar direito e causar dano a outrem, ainda que exclusivamente moral, comete ato ilícito". 
responsabilidade civil daquele ato que violar o contido na norma. Importante por em relevo que a ilicitude não possui como requisito o dolo ou a culpa.

Vale ressaltar que, para a concessão da inibitória em sentença, não é necessário que o perigo seja iminente. A iminência da lesão, a brevidade da prática do ato lesivo ameaçado, é requisito para a concessão da medida liminar, na tutela inibitória antecipada e provisória, ou, ainda, na medida cautelar. Para a inibitória definitiva, concedida em decisão final, basta a atualidade da concreta ameaça da violação, basta a probabilidade - e não a mera possibilidade - de o ato ser, no futuro, praticado, fato este a ser demonstrado no transcorrer da fase instrutória do processo ${ }^{34}$.

\section{No Direito Eleitoral}

É o ramo no qual também se destaca a aplicabilidade da inibição de um ato ilícito.

A legislação eleitoral regulamenta em várias disposições, regras e mecanismos de controle para permitir que o eleitorado possa exercer o livre direito de voto.

Uma situação comum de uso da tutela inibitória ocorre mediante violação do disposto no artigo 36 do Código Eleitoral (Lei 9.504/97), que diz: "a propaganda somente é permitida após o dia 05 de julho do ano da eleição". Assim, é vedado a propaganda extemporânea (que significa o uso de propaganda com fins eleitorais antes da época permitida por lei).

Essa propaganda fora de época ganha relevo quando se observa que o candidato faz uso do expediente de propaganda antes de 05 de julho do ano da eleição, expondo seu nome, sigla partidária, número de candidaturas e propostas políticas sem estar em condição de concorrência qualquer adversário, tornando a corrida eleitoral injusta, pois pode fazer com que este pré-candidato tenha vantagem injusta sobre os demais, como, por exemplo ser mais lembrado - ou ter a simpatia e inclinação inicial de voto - do que os outros que somente na época correta veiculam propaganda ${ }^{35}$.

Analisando essa determinada situação, é certo que esse candidato, que iniciou antes sua propaganda, irá conseguir atingir a mente do eleitor com maior intensidade do que aquele que está veiculando suas propostas juntamente com milhares de outros concorrentes. O que começou antes da época tem maior probabilidade de ser lembrado e escolhido nas urnas pela manobra utilizada.

Para evitar esse benefício pessoal do candidato e, principalmente, para preservar o direito de livre escolha do voto, é que se pode certamente sustentar a inibitória, para que, preenchendo seus requisitos, pode se dar o impedimento do início dessa forma ilegal de propaganda ${ }^{36}$.

\footnotetext{
34. Cristina Rapisarda. Op. Cit., pgs. 136-137.

35. Adriano Soares da Costa explica que o objetivo da propaganda eleitoral é o convencimento do eleitor para a escolha de uma certa candidatura..." COSTA, Adriano Soares da, Teoria da Inelegibilidade e o direito processual eleitoral. Belo Horizonte: Del Rey, 1998, p. 438.
}

36. SARTÓRIO. Élvio Ferreira. Tutela Preventiva (Inibitória) nsa Obrigações de fazer e não fazer. Editora Lumen Juris: Rio de Janeiro, 2007. Pg. 54. 
Antes disso, no período das propagandas eleitorais gratuitas, é muito comum a formulação de pedidos de direito de resposta (art. 58, do Código Eleitoral), que são feitos por candidatos, partidos ou coligações que se consideram prejudicados ilegalmente pelos seus adversários.

O Tribunal Superior Eleitoral, a quem compete apreciar litígios dessa natureza, busca preservar preventivamente a igualdade no pleito. Exatamente por isso, confirma-se a dimensão do poder de polícia das autoridades.

Nesse sentido, temos o julgado do próprio TSE, corroborado a questão da Competência: Acórdão n 46.904, de 28 de janeiro de 2014, Pet. 516-16, Rel. Des. Edson Vidal Pinto: Tutela Inibitória. Facebook. Competência da Justiça Eleitoral:

A Justiça Eleitoral é competente para analisar e julgar a presente ação inibitória para impedir a continuidade do suposto ilícito; (...)

Outro julgado interessante, agora no tocante ao cabimento da tutela inibitória, é quanto à questão da Propaganda Eleitoral Extemporânea. Nesse sentido, temos o julgado do TSE: AC n. 379, de 25 de junho de 2002, do Relator Ministro Sálvio de Figueiredo:

"Direito Eleitoral. Representação. Propaganda Partidária. Utilização do espaço de propaganda partidária com participação de pessoa filiada a partido diverso do responsável pelo programa. Pré-candidato em coligação. Poder de polícia. Exercício dirigido a fazer cessar prática ilegal. Atuação preventiva da Justiça Eleitoral. Provimento da Corregedoria-Geral, que recomenda observância das normas pertinentes às propagandas partidárias e eleitoral e adverte sobre as sanções aplicáveis. Comunicação feita e reiterada aos diretórios nacionais de partidos politicos. Efeito suspensivo indeferido. Agravo interno a que se nega provimento".

Uma situação que nos chamou a atenção foi o julgado pelo Tribunal Regional Eleitoral do Paraná (TRE-PR), Representação $n^{\circ}$ 1568-13.2014.6.16.0000, sendo mais um cabimento da tutela inibitória no direito eleitoral:

“(...) pedido de concessão de tutela antecipada inibitória, 'inaudia altera pars, fundada na alegação de que os representados vêm oferecendo vantagem indevida a eleitores por meio da chamada 'Tenda Digital', recentemente inaugurada, na qual os eleitores poderiam desfrutar, pelo tempo que desejarem, de acesso à internet e estúdio para a produção de fotos.

(...) Requer a concessão de tutela antecipada inibitória para que se determine a cessação imediata do oferecimento de bens e vantagens ao eleitor no Comitê Tenda Digital"

Mais um caso do uso da inibitória no direito eleitoral, cabe a Representação n. 3024 95.2014.6.16.0200:

"A representante alega que a Coligação representada efetuou a gravação de propaganda eleitoral do Candidato Beto Richa, nas dependências de órgão público (...) inclusive com a realização de entrevistas com servidores no exercício de sua função.

Requer a concessão da tutela liminar e inibitória para o fim de determinar aos representados que 'cessem' imediatamente, e, ainda, abstenbam-se de veicular, filmar e produzir novos 
programas eleitorais nos locais e mediante uso de instalaçôes, bens, equipamentos e servidores públicos do Governo do Estado do Paraná ou de seus entes da Administração Indireta".

Em ambos os julgados acima mencionados, percebe-se a finalidade maior da ação inibitória que é a de cessar o ato ilícito. Evidenciando conforme todo o exposto o caráter preventivo inibitório.

Por fim, interessante é relevar que a demonstração de que a culpa e o dano são irrelevantes para a tutela inibitória não tem importância apenas para os fins de analises de seus requisitos de concessão. Também influi diretamente na atividade instrutória das partes e do magistrado, já que tal reconhecimento implica afirmação de que dano e culpa não fazem parte da cognição do juiz. E que, acaso seja requerida a produção de prova com a finalidade de demontrá-la no processo, o magistrado deverá indeferi-la, por se tratar de prova impertinente ao objeto litigioso do processo, em conformidade com o disposto no artigo 130, do $\mathrm{CPC}^{37}$.

Ressaltando que, apenas se existir a previsão da possibilidade de se exigir o cumprimento específico da obrigação correlata ao direito, é que este poderá ser protegido pela tutela de inibição do ato ilegal, conforme nos casos eleitorais analisados.

\section{References}

BAPTISTA DA SILVA, Ovídio Araújo. Racionalismo e tutela preventiva. In Sentença é coisa julgada. $4^{\circ} \mathrm{ed}$. revisada e ampliada. Rio de Janeiro: Forense, 2006.

BEDAQUE, José Roberto dos Santos. Tutela Cautelar e tutela antecipada: tutelas sumárias e de urgência (tentativa de sistematização). São Paulo: Malheiros, 1998.

COSTA, Adriano Soares da. Teoria da Inelegibilidade e o direito processual eleitoral. Belo Horizonte: Del Rey, 1998.

DINAMARCO, Cândido Rangel. A instrumentalidade do processo, 6 ed., São Paulo: Malheiros, 1998.

GONZÁLES Perez, Jesus. El derecho a la tutela jurisdicional, 2. Ed., Madrid: Civitas, 1989.

GRINOVER, Ada Pellegrini; CINTRA, Antônio Carlos de Araújo; e DINAMARCO, Cândido Rangel. Teoria Geral do Processo, Editora Malheiros: São Paulo, 2004.

MAIA, Napoleão Nunes. In Estudos Processuais sobre o Mandado de Segurança. UFC. $2^{\text {a }}$ Edição, 2002.

MARINONI, Luis Guilherme. Tutela Inibitória Individual e Coletiva. $5^{\circ}$ ed., São Paulo: Editora Revista dos Tribunais, 2012.

37. Artigo 130, CPC:"Caberá ao juiz, de ofício ou a requerimento da parte, determinar as provas necessárias à instrução do processo, indeferindo as diligências inúteis ou meramente protelatórias". 
MICHELI, Gian Antonio. Derecho procesal civil. La acción preventiva. Buenos Aires: EJEA, 1970, vol. 4.

RAPISARDA, Cristina. Profille della tutela civile inibitória. Padova: Cedam, 1987

SARTÓRIO. Élvio Ferreira. Tutela Preventiva (Inibitória) nas Obrigações de fazer e não fazer. Editora Lumen Juris: Rio de Janeiro, 2007.

SPADONI, Joaquim Felipe. Ação Inibitória. A ação preventiva prevista no art. 461 do CPC, $2^{\circ}$ ed., São Paulo: RT, 2002. 
Recebido em: $12 / 03 / 2015$

Aceito emः 08/04/2015

\section{Como citar}

SALEH, Paula. A tutela inibitória no Direito Eleitoral Brasileiro. Ballot. Rio de Janeiro: UERJ. Volume 1 Número 1 Junho 2015. pp. 105-118.

Disponível em: [http://www.e-publicacoes.uerj.br/index.php/ballot]

\section{(c) (1) (2) (2)}

A Revista Ballot está licenciada sob uma licença Creative Commons Atribuição - Não Comercial - Compartilha Igual 3.0 Não Adaptada. 